\title{
Дирофиляриоз придаточного аппарата глаза и орбиты
}

\author{
Гришина Е.Е. • Рябцева А.А.
}

\author{
Гришина Елена Евгеньевна - д-р мед. \\ наук, профессор, вед. науч. сотр. \\ офтальмологического отделения' \\ $\triangle 129110$, г. Москва, ул. Щепкина, \\ 61/2-11, Российская Федерация. \\ Тел.: +7 (905) 7031863. \\ E-mail: eyelena@mail.ru \\ Рябцева Алла Алексеевна - д-р мед. \\ наук, профессор, руководитель \\ офтальмологического отделения
}

' ГБУЗ МО «Московский областной научно-исследовательский клинический институт им. М.Ф. Владимирского»; 129110, г. Москва, ул. Щепкина, 61/2, Российская Федерация

\begin{abstract}
Актуальность. Дирофиляриоз - редкий вид гельминтоза, вызываемого нематодами Dirofilaria repens и Dirofilaria immitis. Чаще всего личинка дирофилярия располагается под конъюнктивой. В этом случае диагноз не вызывает затруднения. При локализации гельминта в тканях век или орбиты, как правило, устанавливается ошибочный диагноз новообразования.
\end{abstract}

Цель - описание основных симптомов дирофиляриоза придаточного аппарата глаза и оценка результатов его лечения.

Материал и методы. В исследование вошли 43 больных с дирофиляриозом (19 мужчин и 24 женщины в возрасте от 25 до 83 лет).

Результаты. Клинические симптомы дирофиляриоза определялись локализацией паразита и токсико-аллергической реакцией на продукты его жизнедеятельности. При расположении гельминта под конъюнктивой был виден подвижный (у 11 больных) или погибший (у 2 больных) паразит в виде свернутой белой ниточки на фоне выраженной конъюнктивальной инъекции и хемоза. У 2 больных был обнаружен подвижный гельминт под кожей век. При локализации дирофилярия в толще века (7 больных) или в переднем отделе орбиты (20 больных) пальпировалось безболезненное образование, спаянное с подлежащими тканями. Для дирофиляриоза было характерно изменение клинических симптомов при миграции гельминта: развитие отека век, появление гиперемии кожи век и увеличение экзофтальма. Через несколько дней явления отека век и тканей орбиты стихали, а гельминтную гранулему выявляли на новом месте. Удаление гельминта и его гранулемы без дополнительного медикаментозного лечения привело к полной санации всех больных.

Заключение. Дирофиляриоз должен быть включен в дифференциально-диагностический ряд с воспалительными заболеваниями придаточного аппарата глаза или объемным процессом в орбите. Единственным методом лечения дирофиляриоза у человека является удаление гельминта и/или его гранулемы.

Ключевые слова: гельминт, гельминтная гранулема, дирофиляриоз, конъюнктива, веки, орбита.

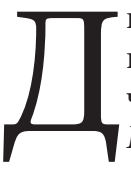

ирофиляриоз относится к редким видам гельминтоза, вызываемого круглыми червями - нематодами - рода Dirofilaria:

D. repens и D. immitis. Название происходит от латинских слов diro и filum, что означает «злая нить». Действительно, внешне паразит имеет вид белой тонкой ниточки, длина которой может достигать $40 \mathrm{~cm}$.

Основным хозяином дирофилярия являются собаки, промежуточным - комары. Человек заражается от больной собаки через укусы комаров, то есть заболевание передается трансмиссивным путем. Обычно заражение происходит во время пребывания на природе: при выполнении сельскохозяйственных работ, отдыхе на даче, на рыбалке или охоте. Человек - тупиковая ветвь в цикле развития гельминта, так как в организме человека никогда не происходит размножения дирофилярия.

Излюбленной локализацией паразита является придаточный аппарат глаза. Чаще всего личинка дирофилярия располагается под конъюнктивой. В этом случае диагноз не вызывает затруднения. При локализации гельминта в тканях век или в орбите, как правило, устанавливается ошибочный диагноз новообразования. 


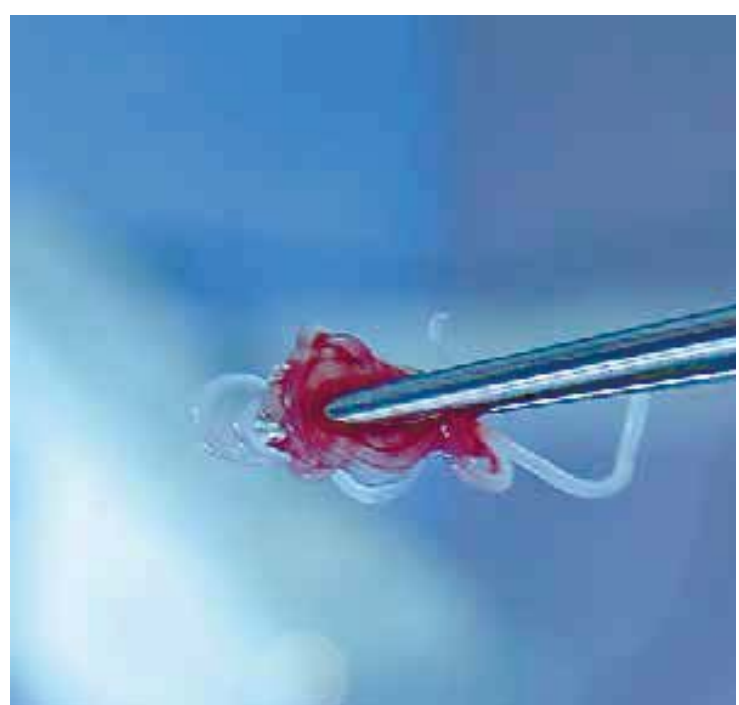

Рис. 1. Нематод Dirofilaria repens. Внешний вид

Цель - описание основных симптомов дирофиляриоза придаточного аппарата глаза и оценка результатов его лечения.

\section{Материал и методы}

За период с 2008 по 2013 г. мы диагностировали дирофиляриоз у 43 больных. У 14 больных гельминт локализовался под конъюнктивой, у 7 в толще века, у 2 - под кожей века и у 20 - в переднем отделе орбиты. В 23 наблюдениях гельминт был живым, в том числе у 8 больных живой гельминт был удален из мягких тканей орбиты.

Возраст пациентов колебался от 25 до 83 лет (медиана составила 56 лет), мужчин было 19, женщин - 24 (соотношение мужчин и женщин 1:1,3).

Диагноз дирофиляриоза у 28 больных был установлен на основании идентификации удаленного живого или погибшего паразита. В Московском научно-исследовательском институте паразитологии гельминт был определен как нематод D. repens (рис. 1). У остальных 15 больных диагноз дирофиляриоза был установлен при гистологическом исследовании частей паразита в гельминтной гранулеме (рис. 2).

\section{Результаты}

Предполагаемый промежуток времени с момента укуса комара до развития местных симптомов составил от 2 до 4 месяцев. Все больные были либо жителями Московской области, либо москвичами, проводившими летний отдых в Московской области и в соседних регионах. Клинические

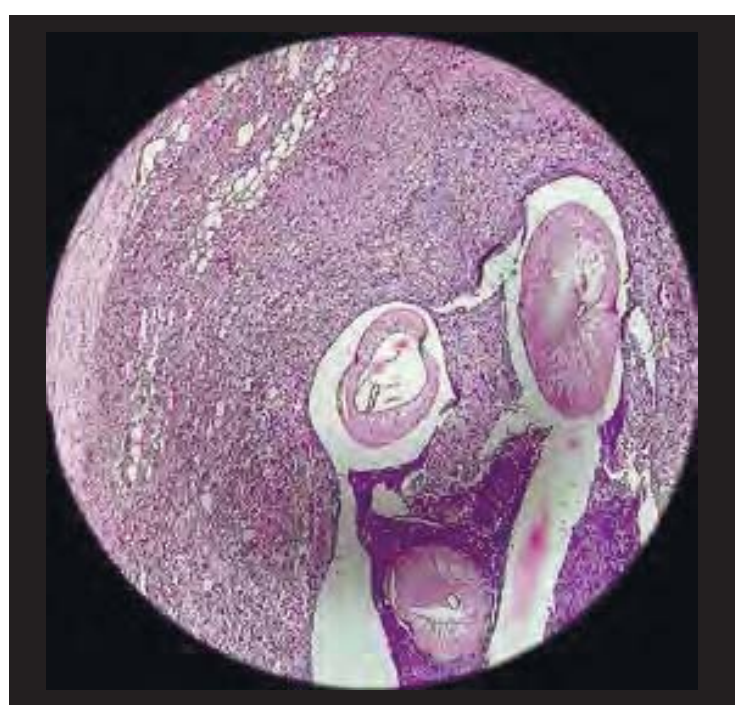

Рис. 2. Гистологический препарат гельминтной гранулемы с частями Dirofilaria repens. $\times 10$, окраска гематоксилином и эозином

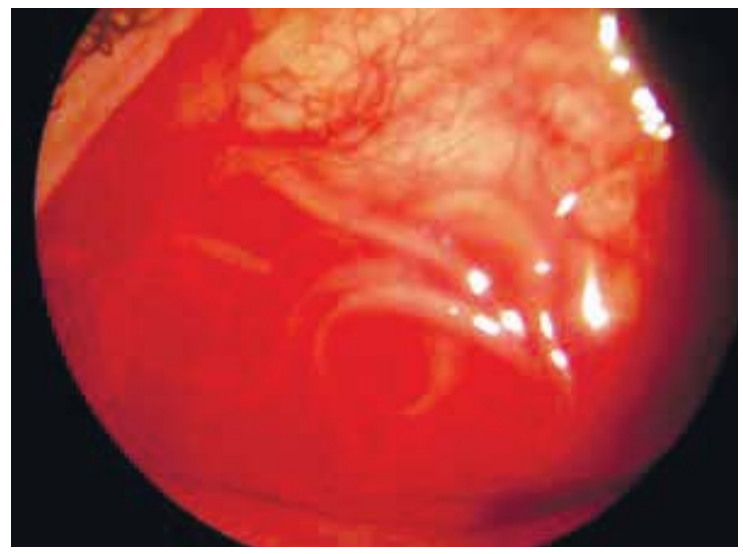

Рис. 3. Dirofilaria repens под конъюнктивой

симптомы дирофиляриоза определялись локализацией паразита и токсико-аллергической реакцией на продукты его жизнедеятельности. При расположении дирофилярия под конъюнктивой в свете щелевой лампы был хорошо виден подвижный (у 11 больных) или погибший неподвижный (у 2 больных) паразит в виде свернутой белой ниточки на фоне выраженной инъекции конъюнктивальных сосудов и хемоза (рис. 3). Токсико-аллергический конъюнктивит не сопровождался наличием какого-либо отделяемого в конъюнктивальной полости. У 1 больного вокруг погибшего паразита в области слезного мясца образовалась гранулема (рис. 4).

У 2 больных был обнаружен подвижный гельминт под кожей век. Его перемещение 


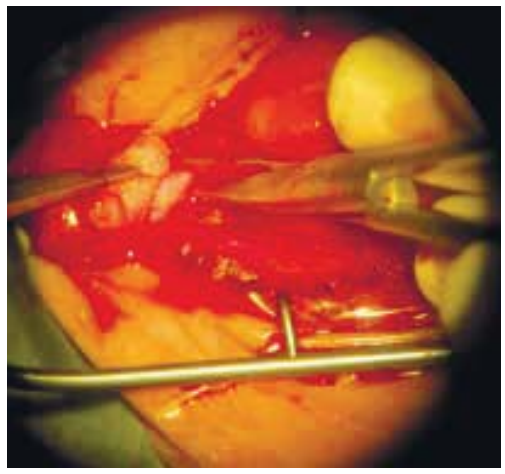

Рис. 4. Гельминтная гранулема в области слезного мясца

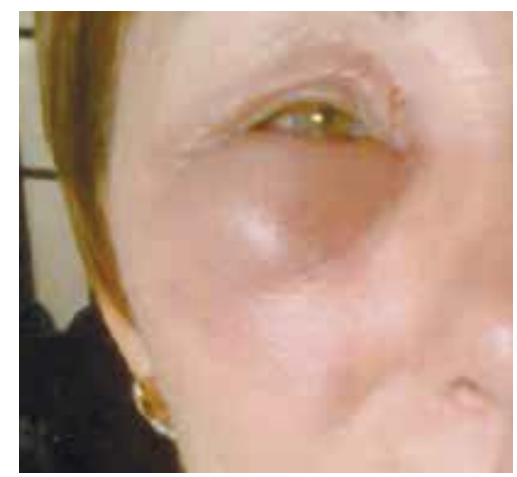

Рис. 5. Больная М. 57 лет. Токсикоаллергический отек век при миграции гельминта

сопровождалось выраженным болевым симптомом. При локализации дирофилярия пресептально в толще века (7 больных) или в переднем отделе орбиты (20 больных) пальпировалось безболезненное образование, спаянное с подлежащими тканями. Миграция гельминта приводила к изменению клинической симптоматики. В связи с перемещением паразита у 10 больных мы наблюдали острое развитие отека век, гиперемию кожи век и увеличение экзофтальма (рис. 5). Через несколько дней отек век и тканей орбиты уменьшался, а гельминтную гранулему выявляли на новом месте. Гибель гельминта также сопровождалась развитием токсико-аллергического отека придаточного аппарата глаза и тканей орбиты.

Всем больным было проведено хирургическое лечение - удаление гельминта и его гранулемы. В послеоперационном периоде назначали инстилляции фторхинолонов (моксифлоксацин), нестероидных противовоспалительных препаратов в форме капель (индометацин, непафенак) и противоаллергических препаратов (олопатадин). Внутрь рекомендовали антигистаминные препараты. Общую противовоспалительную терапию не проводили. В сроки от 2 до 10 дней (в зависимости от первоначальной локализации гельминта) наблюдали полное стихание всех симптомов.

\section{Обсуждение}

Проблема дирофиляриоза заключается в его широкой распространенности и отсутствии необходимых мер по выявлению и дегельминтации больных животных. Дирофиляриоз встречается повсеместно. Имеются сведения о его регистрации в странах Старого Света [1]. Однако этот гельминтоз преимущественно выявляется на юго-востоке Европы, в Российской Федерации и странах СНГ $[2,3]$. Отмечается постоянное увеличение частоты заболеваемости дирофиляриозом. Так, по данным Т.И. Авдюхиной и соавт., в течение 40 лет с момента первой публикации (с 1915 по 1955 г.) было описано 15 случаев дирофиляриоза, из них 12 - глазного. В последующие 40 лет (с 1956 по 1995 г.) было зарегистрировано 95 случаев дирофиляриоза, в том числе 38 - глазного [4]. В своей статье 2014 г. В.П. Сергеев и соавт. приводят данные уже о 850 случаях дирофиляриоза, зафиксированного в 42 районах Российской Федерации [3].

Заражение собак происходит при укусе комара. Личинки в подкожной жировой клетчатке животного превращаются в неполовозрелые особи, которые мигрируют в легкие и сердце собак, где через 5-6 месяцев превращаются в половозрелые особи и откладывают микрофилярии в кровь животных. При укусе комаром больного животного микрофилярии попадают в кишечник, оттуда в мальпигиевы сосуды, а затем в нижнюю губу комара. Здесь они вступают в инвазивную стадию развития. Заражение нового животного происходит при укусе комара. Цикл замыкается. Человек заражается при укусе инвазированным комаром. В организме человека приживаются единичные личинки, и реакция на их наличие и развитие минимальная. Как правило, у человека выживает только одна особь - неполовозрелая самка.

Излюбленной локализацией дирофилярий (D. repens) является бульбарная конъюнктива и периорбитальные ткани $[2,5]$. В редких случаях гельминт выявляют в стекловидном теле глаза [6, 7,8].

Дирофиляриоз характеризуется медленным развитием и хроническим течением. Местные симптомы обусловлены локализации гельминта и присоединением вторичной инфекции, либо токсико-аллергической реакцией на гибель или перемещение гельминта. При локализации живого дирофилярия под конъюнктивой либо под кожей век правильный диагноз не вызывает затруднений. При локализации в мягких тканях век или орбиты, как правило, устанавливается ошибочный диагноз новообразования [9]. В серии из 50 больных, описанных в статье Т.И. Авдюхиной и соавт., только у 4 был установлен правильный диагноз дирофиляриоза [4]. Важным признаком дирофиляриоза является изменчивость симптомов: появление и стихание токсико-аллергического отека век и изменение степени экзофтальма. Нередко на новом месте возникает уплотнение в толще века или появляется доступное пальпации образование в полости орбиты. Изменение 
симптомов связано с миграцией гельминта или с его гибелью. В связи с тем, что в организме человека паразитирует только одна неполовозрелая особь, размножения гельминта не происходит. Микрофилярии в крови человека не обнаруживают. Удаление гельминта и его гранулемы без дополнительного медикаментозного лечения приводит к полной санации больных.

\section{Заключение}

Дирофиляриоз должен быть включен в дифференциально-диагностический ряд при обследовании больных с воспалительными заболеваниями придаточного аппарата глаза или объемным процессом в орбите. Единственным методом лечения дирофиляриоза у человека является удаление гельминта и/или его гранулемы. (\$)

\section{Литература (References)}

1.Pampiglione S, Rivasi F. Human dirofilariasis due to Dirofilaria (Nochtiella) repens: an update of world literature from 1995 to 2000 Parassitologia. 2000;42(3-4):231-54.

2.Sałamatin RV, Pavlikovska TM, Sagach OS, Nikolayenko SM, Kornyushin VV, Kharchenko VO, Masny A, Cielecka D, Konieczna-Sałamatin J, Conn DB, Golab E. Human dirofilariasis due to Dirofilaria repens in Ukraine, an emergent zoonosis: epidemiological report of 1465 cases. Acta Parasitol. 2013;58(4):592-8.

3.Sergiev VP, Supriaga VG, Bronshteĭn AM, Ganushkina LA, Rakova VM, Morozov EN, Fedianina LV, Frolova AA, Morozova LF, Ivanova IB, Darchenkova NN, Zhukova LA. Results of studies of human dirofilariasis in Russia. Med Parazitol (Mosk). 2014;(3): 3-9.

4. Авдюхина ТИ, Лысенко АЯ, Супряга ВГ, Постнова ВФ. Дирофиляриоз органа зрения: реестр и анализ 50 случаев в Российской Федерации и странах СНГ. Вестник офтальмологии. 1996;112(3):35-9.

(Avdyukhina TI, Lysenko AYa, Supryaga VG, Postnova VF. [Dirofilariasis of the eye: register and analysis of 50 cases in the Russian Federation and CIS states]. Vestnik oftal'mologii. 1996;112(3):35-9. Russian).

5. Pampiglione S, Rivasi F, Angeli G, Boldorini $R_{,}$ Incensati RM, Pastormerlo M, Pavesi M, Ramponi A. Dirofilariasis due to Dirofilaria repens in Italy, an emergent zoonosis: report of 60 new cases. Histopathology. 2001;38(4):344-54.
6. Глинчук ЯИ, Форофонова ТИ, Роуман ВА. Случай дирофиляриоза стекловидного тела. Офтальмохирургия. 1992;(4):59-62. (Glinchuk Yal, Forofonova TI, Rouman VA. [Difilariasis of vitreous body: a case report]. Oftal'mokhirurgiya. 1992;(4):59-62. Russian).

7. Kalogeropoulos CD, Stefaniotou MI, Gorgoli KE, Papadopoulou CV, Pappa CN, Paschidis CA. Ocular dirofilariasis: a case series of 8 patients. Middle East Afr J Ophthalmol. 2014;21(4):312-6. 8. Gorezis S, Psilla M, Asproudis I, Peschos D, Papadopoulou C, Stefaniotou M. Intravitreal dirofilariasis: a rare ocular infection. Orbit. 2006;25(1):57-9.

9. Davis R, Barsoumian A, Mauffray R, Caldwell M, Drayna P, Crosson J. Dirofilaria Presenting as Orbital Mass. Orbit. 2014;22:1-3.

\title{
Dirofilariasis of ocular adnexa and orbit
}

\author{
Grishina E.E. • Ryabtseva A.A.
}

Grishina Elena Evgen'evna - MD, PhD Professor, Leading Research Associate, Ophthalmology Department ${ }^{1}$

$\square$ 61/2-11 Shchepkina ul., Moscow, 129110, Russian Federation.

Tel.: +7 (905) 7031863.

E-mail: eyelena@mail.ru

Ryabtseva Alla Alekseevna - MD, PhD

Professor, the Head of the Ophthalmology Department ${ }^{1}$
Background: Dirofilariasis is a rare helminthosis caused by nematode worms Dirofilaria repens and Dirofilaria immitis. Larvae of dirofilaria are most frequently localized subconjunctivally and are easily diagnosed. Localization of the helminth deep in eyelid or orbital tissue usually leads to false diagnosis of neoplasm.

Aim: To describe main symptoms of dirofilariasis of ocular adnexa and orbit and to assess treatment outcomes.

Materials and methods: 43 patients with dirofilariasis (19 men, 24 women, age 25-83 years old) were included.

Results: Clinical symptoms of dirofilariasis were related to helminth localization and toxicoallergic reaction to its metabolic by-products. In case of subconjunctival localization, mobile (in 11 patients) or dead (in 2 patients) parasites presented as a twisted white fiber with background conjunctival injection and chemosis. In 2 patients, mobile parasites were found under the eyelid skin. In patients with dirofilaria deep in eyelid tissues (in 7 patients) or in anterior portion of the orbit (20 patients), painless mass attached to subjacent tissues was detected. Migration of the helminth was associated with exacerbated clinical symptoms: eyelid edema, eyelid skin hyperemia and increased exophthalm. After several days, eyelid and orbital edema resolved, and a new localization of helminth-induced granuloma was determined. Extraction of parasite and granuloma resulted in full recovery in all patients, no medical treatment was required.

Conclusion: Dirofilariasis should be regarded as one more possible cause of orbital inflammation or mass. The only method of treatment of dirofilariasis is extraction of parasite and/or helminth-induced granuloma.

Key words: helminth, helminth-induced granuloma, dirofilariasis, conjunctiva, eyelids, orbit. 